\title{
REPRESENTASI “NAZAR” DALAM FILM INSYA ALLAH SAH KARYA BENNI SETIAWAN
}

\author{
Giovani \\ Program Studi Televisi Dan Film Universitas Potensi Utama \\ giovani.sahri@gmail.com
}

\begin{abstract}
ABSTRAK
Pada saat ini kebudayaan dan sebuah realitas sosial adalah seuah ideologi yang sering direpresentaikan dalam sbuah film atupun media lainnya, tidak terlepas itu hanya untuk kepentingan individu maupun kelompok. Representasi adalah sbuah penggambaran, perwakilan atau gambaran. Secara sederhana, representasi dapat diartikan sebagai gambaran mengenai suatu hal yang terdapat dalam kehidupan yang digambarkan melalui suatu media.Film Insya Allah Sah adalah salah satu dari sekian banyak film dan media televisi lainya yang mengadopsi dan memasukan nilai-nilai dari sebuah realitas sosial, yang mana di dalam film Insya Allah sah menggambarkan ulaung konsep Nazar yang terdapat di tengah masyarakat untuk dijadikan sebuah representasi dalam film. Penggambaran ulang Nazar yang muncul dan konsep pelaksanaan Nazar yang muncul dalam film Insya Allah Sah memberikan sebuah pesan terhadap masyarakat dalam menepati dan merealisasikan Nazar yang telah diucapan. Dalam kasus Representasi Nazar pada film Insya Allah Sah karya Benni steiawan, representasi yang di munculkan melibatkan karakter wanita yang memberikan efek hijrah pada seorang wanita dan memberikan pesan bahwa Sangat penting dalam menepati sebuah Nazar
\end{abstract}

Kata Kunci : Film Insya Allah Sah, Nazar, Representasi

\begin{abstract}
At present, community and socialization are ideologies that are often represented in a film or other media, not limited to individual or group interests. Representation is a description, representation or picture. In simple terms, representation can be interpreted as reflecting various things that exist in life that are portrayed through the media. Film Insya Allah Sah is one of the many films and other media that are connected and adjust the values of a social reality, which in the film Insha Allah, the concept of Nazar is valid in the community to be a representation in the film. The regrinding of Nazar that emerged and the concept of the implementation of Nazar that appeared in the film Insya Allah Sah gave a message to the community in fulfilling and realizing the Nazar that had been sent. In the case of the Nazar Representation of Benni steiawan's Insha Allah Sah movie, the representation that came from women gave the effect of emigrating a woman and gave the message that it was very important in keeping a Nazar
\end{abstract}

Keywords: Film Insya Allah Sah, Nazar, Representation

\section{PENDAHULUAN}

Media film adalah salah satu wadah yang bertujuan untuk menyampaikan informasi yang tersirat maupun tidak tersirat, dan film juga berfungsi untuk menuangkan nilai-nilai sebuah realitas sosial yang terdapat di tengah-tengah masyarakat, hal tersebut tidak terlepas dari peran media massa yang sangat berpengaruh terhadap dunia, yang mana komunikasi 
yang baik pada era saat ini ialah media. Oleh sebab itu banyaknya film yang menjadi sarana penyebaran informasi digunakan dalam merepresentasikan hal-hal sosial yang

terdapat dalam lingkungan masyarakat. Beberapa film yang merepresentasikan realitas sosial atau pun mengankat sebuah kisah kebudayaan dan kehidupan seperti : Film Naga Bonar karya Benni Setiawan, Film 5 Cm Karya Rizal Mantovani dan lain sebagainya yang mana film-film tersebut mengkonstruksi sebuah cerita ke dalam sebuah film.

Adapun tujuan dari sebuah representasi adalah menggambarkan ulang cerita ke dalam sebuah film, yang mana hal tersebut adalah cara dalam rangka menyampaikan sebuah pesan, seperti film-film yang tayang di Box Ofice maupun televisi nasional. Film merupakan media penyampaian pesan yang dapat diterima berbagai kalangan, yang mana di dalam film mampu mngeluarkan makna dari sebuah cerita yang tergambar dalam film. Adapun makna yang tersirat dalam sebuah film dapat dirasakan oleh individu masingmasing penonton, film dapat dimaknai secara sosial, religi dan kultur yang mana hal teresubut mampu menggiring opini masyarakat terhadap realitas masyarakat terhadap zamanya.

Film Insya Allah Sah adalah film yang bergenre religi komedi yang disutradarai oleh Benni Setiawan, film Insya Allah Sah adalah film yang mengangkat sebuah makna dan pesan dari nazar yang direpresentasikan ke dalam sebuah film. Film Insya Allah Sah ialah film yang di transformasikan dari sebuah novel yang berjudul INSYA ALLAH SAH! Yang di tulis oleh Achi TM, yang mana inspirasi dari penulisan novel juga di dapati dari dampak Achi TM bernazar, oleh karena itu representasi Nazar dalam film Insya Allah Sah sangat kental terdapat didalam film . tidak terlepas dari representasi Nazar tetapi di dalam film Insya Allah Sah juga menerpakan dan memberikan gambaran seberapa penting nazar harus di perhatikan.

Nazar berasal dari kata arab (naw-zeer) yang artinya "bernazar", dalam bahasa arab disebut "to vow" (Oemarr Bakry, 249 : 1974). Dalam kamus bahasa Indonesia "Nazar" berarti : "janji hendak berbuat sesuatu apabila telah tercapai maksudnya ; Kaul; membayar (melepasi, menunaikan), melakukan apa yang sudah dijanjikan (Poerwadarminta, 667 : 1999). Dalam pemahaman Fiqh Nazar ialah mengingat, pemahaman dari hal itu adalah mewajibkan kepada individu seseorang untuk melakukan suatu perbuatan untuk bermaksud mendekatkan diri kepada sang pencipta dengan mengucapkan dan mengutarakan lafadz Nazar, sesuai dengan ketentuan yang diharuskan. Film Insya Allah Sah merepresentasikan nazar ke dalam film memberikan sebuah dramatisasi cerita dalam menggiring konsep cerita religi kedalam konflik sebuah perjanjian seorang muslimah dalam sebuah kehidupan yang lebih baik.

Representasi berasal dari bahasa Inggris, representation,yang berarti perwakilan,gambaran, atau penggambaran. Secara sederhana, representasi dapat diartikan sebagai gambaran mengenai suatu hal yang terdapat dalam kehidupan yang digambarkan melalui suatu media. (Mulyana, 2014: 96). Representasi menurut Chris Barker adalah konstruksi social yang mengharuskan kita mengeksplorasi pembentukan makna tekstual dan menghendaki penyelidikan tentang cara dihasilkannya makna pada beragam konteks. Representasi dan makna budaya memiliki materialitas tertentu. Mereka melekatpada bunyi, prasasti, objek, citra, buku, majalah, dan program televisi. Mereka diproduksi,ditampilkan,digunakan, dan dipahami dalam konteks sosial tertentu (Mulyana, 2014:97). 
Representasi merupakan hubungan antara konsep-konsep dan bahasa yang menunjuk pada dunia yang sesungguhnya dari suatu objek, realitas atau pada dunia imajiner tentang obyek fiktif, manusia atau peristiwa. Suatu makna diproduksidari konsepkonsep dalam pikiran seorang pemberi makna melalui bahasa (Hermawan, 2011:234).

David Croteau dan William Hoynes menyatakan bahwa representasi merupakan hasil dari suatu proses penyeleksian yang menggaris bawahi hal-hal tertentu dan hal lain diabaikan. Dalam representasi media, tanda yang akan digunakan untuk melakukan representasi tentang sesuatu mengalami proses seleksi. Mana yang sesuai dengan kepentingan dan pencapaian tujuan komunikasi, ideologisnya itu yang digunakan sementara tanda-tanda lain diabaikan (dalam Wibowo, 2011:123).

Film Insya Allah Sah ialah film yang diperankan oleh banyak pemeran diantaranya adalah Silvy, Dion dan Raka. Tiga pemeran yang disebutkan adalah pemeran yang membawa karakter penting dan menjadi titik fokus dalam jalanya cerita dalam film Insya Allah Sah. Film Insya Allah Sah menceritikan mengenai seorang gadis yang bernama Silvy yang ingin menikah dengan Dion, Dion ialah seorang lelaki yang menjadi tambatan hatinya sejak lama dan di suatu waktu Dion ingin melamar Silvy untuk menikahinya, dan pada saat itu juga Silvy bergegas menuju kantor Dion untuk menemui Dion, pada saat Silvy menaiki lift yang ada di kantor Dion, lift yang digunakan Silvy mendadak mati dan tidak berfungsi, pada saat itu Silvy sedang bersama dengan seorang lelaki yang bernama Raka, Raka adalah seorang lelaki yang berkarakter religious serta suka mengganggu Silvy dan Dion. Raka adalah lelaki yang menjadi awal konflik dalam cerita film Insya Allah karena Raka penyebab Silvy bernazar ketika sedang terjebak dalam lift yang mati. Pada saat terjebak silvy dan raka mulai kalud dan merasa terancam dengan keselamatan mereka berdua, Oleh karena itu Nazar menjadi sebuah salah satu cara bagi mereka untuk selamat dari lift yang sedang mati tersebut. Dalam Film Insya Allah Sah, Nazar menjadi sebuah alasan khusus dalam berjalanya cerita yang terjadi sehingga sampai dalam klimaks dan akhir dalam film Insya Allah Sah.

Berdasarkan cerita dan alur yang tertuang pada film Insya Allah Sah menggambarkan bagaimana konsep Nazar dan bagaimana cara menepati Nazar yang tergambarkan pada alur yang terjadi pada film, serta apa dampak dari tidak menepati Nazar yang telah diucapkan sebelumnya. Maka dari itu penelitian ini di lakukan dalam tahapan untu mengetahui konstruksi narasi dan alur yang menggambarkan konsep representasi Nazar dalam film Insya Allah Sah. Adapaun representasi menurut Jones dan Knuth (1991) bahwa representasi adalah gambaran atau bentuk dari suatu keadaan atau aspek dari sebuah kondisi konflik yang digunakan untuk menemukan solusi dalam permasalahan yang dituangkan kedalam berupa obyek tertentu.

Representasi Nazar yang terdapat dalam film Insya Allah Sah Sutradara Benni Setiawan sangat menarik untuk diteliti karena memiliki nilai penting dan khusus dalam berjalanya cerita yang terdapat dalam film, konsep penyampaian pentingnya melakukan Nazar atau janji yang telah diucapkap serta, dampak yang terjadi ketika tidak menepati Nazar yang telah di ucapkan, sehingga adegan serta alur dalam film menjadi sebuah jawaban dalam konsep Nazar yang representasikan dalam film Insya Allah Sah sutradara Benni Setiawan. 


\section{STUDI LITERATUR}

Penulisan penelitian ini menggunakan beberapa refrensi untuk menambah kerealitasan dalam pencarian data dan dalam memperbanyak pembendaharaan intelektual serta menambah kedalaman analisis dalam pemecahan masalah didalam penelitian ini di antara lain yaitu: (1). Harry Anofrina, Skripsi "Analisis Semiotika Representasi Persahabatan Dalam Film "Hugo"”,2014. (2).Journal Vol. VI, No.1 Juni 2016: 47 - 66 "Represaentasi Perempuan Dalam Iklan "Fair Of Lovely" Versi NIkah Atau S2". dalaam jurnal ini membahas tentang representasi realita sahabat yang di tuangkan dalam Iklan. (3). Journal Proporsi Vol. 3, No.1 Juni 2017: 47 - 66 "Represaentasi Rasisme Perempuan Pada Flilm "Nothing Special” Karya Ferthamansyah"., (4). Abdullah bin nuh dan Oemar Bakry, Kamus (Arab, Indonesia, Inggris), Jakarta: PT. Mutiara Sumber Widya, cet. Ke-4, 1974.

\section{PEMBAHASAN}

Film Insya Allah Sah adalah film yang ditransformasikan dari sebuah novel yang berjudul Insya Allah Sah!. Novel Insya Allah Sah yang ditulis oleh Achi TM mengambarkan kisah yang di alami oleh penulis yakni penulis merepresentasikan kejadian yang pernah di alami Achi TM ke dalam cerita dalam novel, yang mana Achi TM pernah bernazar pada saat kehilangan laptop di bandara. Pada saat itu Achi TM bernazar jika laptop yang hilang tersebut kembali ditemukan, Achi TM akan menulis novel yang bertemakan Religi, dan pada hari yang sama, laptop Achi TM di temukan oleh peugas penjaga Bandara. Oleh sebab itu cerita yang yang dituangkan di dalam film adalah hasil representasi dari realita sosial atau konflik yang terjadi pada diri seseorang,

Representasi Nazar yang diimplementasikan pada film Insya Allah Sah, menjelaskan sebuah konsep yang seharusnya diterapkan pada seseorang ketika sudah bernazar untuk melakukan sesuatu demi mendapatkan apa yang diinginkan atau menyelesaikan sebuah permasalahan yang menyebabkan individu merasa terancam. Pada film Insya Allah Sah terdapat beberapa scene yang menunjukan sebuah konsep penerapan Nazar yang diimplementasikan ke dalam film Insya Allah Sah yang menggambarkan betapa pentingnya menpati janji ketika bernazar dan dampak yang terjadi ketika tidak menepati Nazar yang di ucapkan. Di dalam film Insya Allah Sah terdapat adegan yang mnggambarkan scene tentang bernazar yang digambarkan oleh Silvy dan Raka ketika sedang terjebak dalam lift yang mati, dan scene tersebut adalah awal dari konflik Nazar yang disampaikan dalam film Insya Allah Sah. Adapun adegan yang menggambarkan Silvy dan Raka sedang bernazar di dalam lift dapat di lihat pada gambar 1 yang mana dalam adegan tersebut Raka dan Silvy sedang terjebak dalam lift yang matiu dan mereka merasa terancam ketika di dalam berada di dalam lift, adapun Raka sebagai seseorang yang dikisahkan sebagai seseorang yang religius, menggiring Silvy dan menasehati Silvy untuk bernazar yang tujuanya agar Allah dapat menyelamatkan mereka dari keadaan tersebut.

\section{A. Synopsis}

Film Insya Allah Sah akan menceritakan tentang kehidupan seorang perempuan bernama Silvi (diperankan Titi Kamal), yang bekerja sebagai designer baju yang sudah sukses dan begitu juga kehidupannya sudah sempurna dengan adanya kekasih hati bernama Dion (diperankan oleh Richard Kyle). Namun masih ada angan-angan Silvi yang belum tercapai yaitu melangsungkan pernikahan dengan Dion. Ketika Silvi ingin menemui Dion, tiba-tiba Ia harus menghadapi peristiwa yang mengubah hidupnya. Ia terjebak didalam sebuah lift bersama seorang pria yang religius, lugu dan aneh bernama Raka (diperankan 
Pandji Pragiwaksono). Raka bekerja untuk Dion, sesaat itu Silvo mencoba segala cara agar segera keluar dari lift tersebut karena tidak nyaman.

Silvi kemudian bernazar, apabila selamat Ia akan mengubah kehidupannya menjadi seorang perempuan muslimah yang taat menjalankan segala perintah Allah. Seketika pintu Lift tiba-tiba terbuka dengan sendirinya. Semenjak kejadian di lift tersebut, Silvi selalu dibayang-bayangi oleh Raka akan Nazar yang Ia ucapkan. Hingga musibah tiba-tiba menimpa Silvi, Raka yang akhirnya menolong Silvi. Hal ini tidak sepihak dengan Dion atas nazar Silvi (Sumber: benni setiawan).

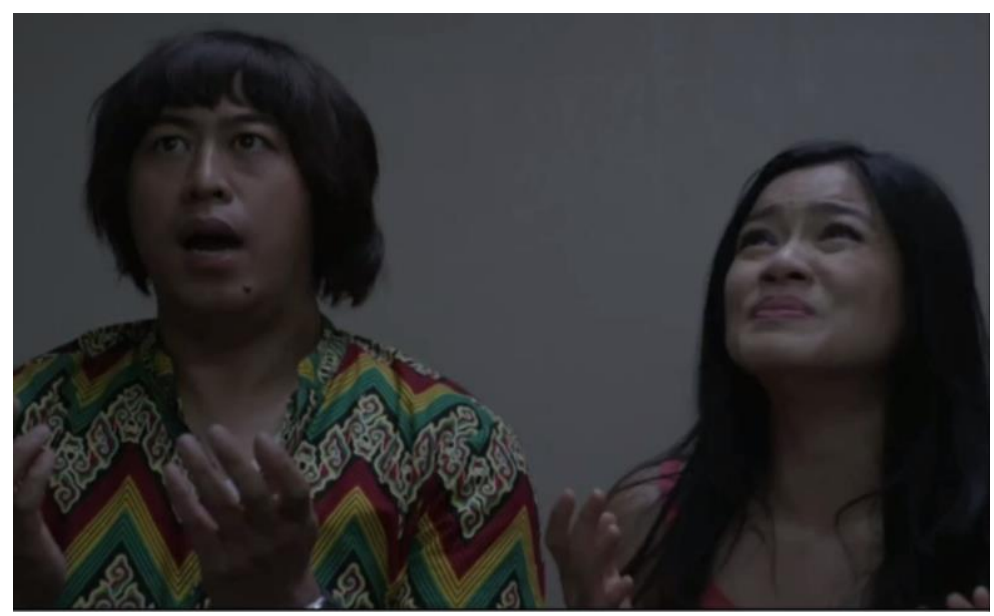

Gambar 1. Raka dan Silvy Sedang berdoa di dalam Lift Yang Mati (Sumber : Giovani, Capture Film Insya Allah Sah, 2018)

Pada Gambar 1, menunjukan keadaan atau adegan Raka dan Silvy sedang menadahkan kedua tangan untuk memohon agar pintu lift dibuka, tetapi pintu lift juga belum terbuka, dan pada adegan ini Silvy dan Raka mulai kalud dan ketakutan sehinnga mereka menyerah dan berhenti sejenak untuk berdoa dan terduduk di bawah yang di tunjukan pada gambar 2 .

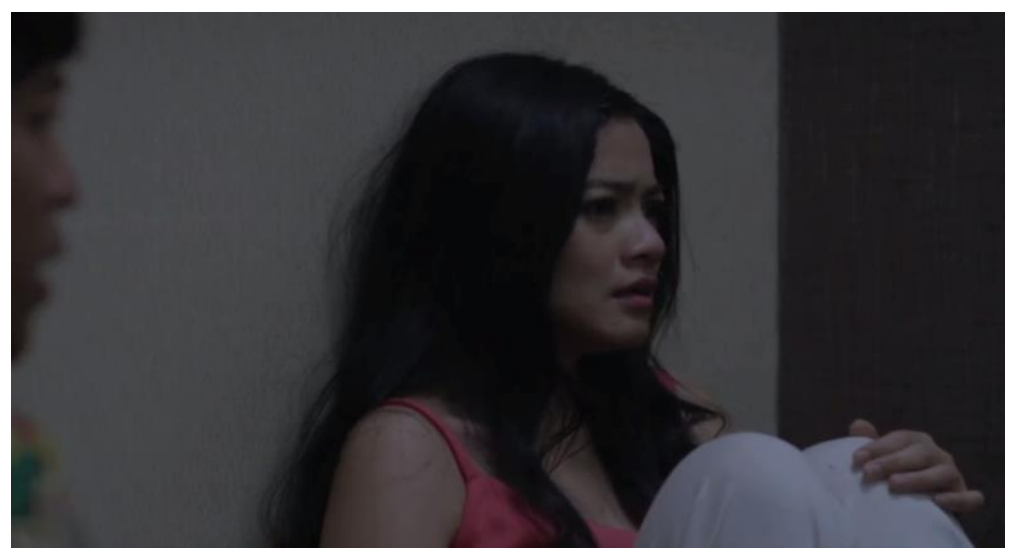

Gambar 2. Silvy Sedang Bernazar di dalam Lift Yang Mati (Sumber : Giovani, Capture Film Insya Allah Sah, 2018)

Gambar 2 menunjukan sebuah rasa keterpurukan yang dirasakan Silvy yang lelah berdoa sehinnga ia merasa menyerah sehingga terduduk dibawah lantai lift yang sedang mati. Oleh karena itu terdapat sebuah penendaa sebuah konflik yang terdapat pada adegan yang ditampilkan pada gambar 2, hal tersebut tepat adanya hal yang di rasakan oleh 
penulis novel Insya Allah Sah yati Achi TM yang merasakan hal yang keterpurukan pada saat Laptop yang dimiliki hilang seketika, dan hal tersebut juga ditampilkan pada adegan yang tergambar pada film Insya Allah Sah. Dan hal tersebut adalah salah satu konsep dari representasi kisah yang akan membawa pada konsep Nazar yang dituangkan pada film Insya Allah Sah.

Adegan yang terdapat pada Gambar 2 adalah sebuah proses yang akan membawa pada Nazar yang di ucapkan oleh Silvy dan adegan tersebut dapat di lihat pada gambar 3 .

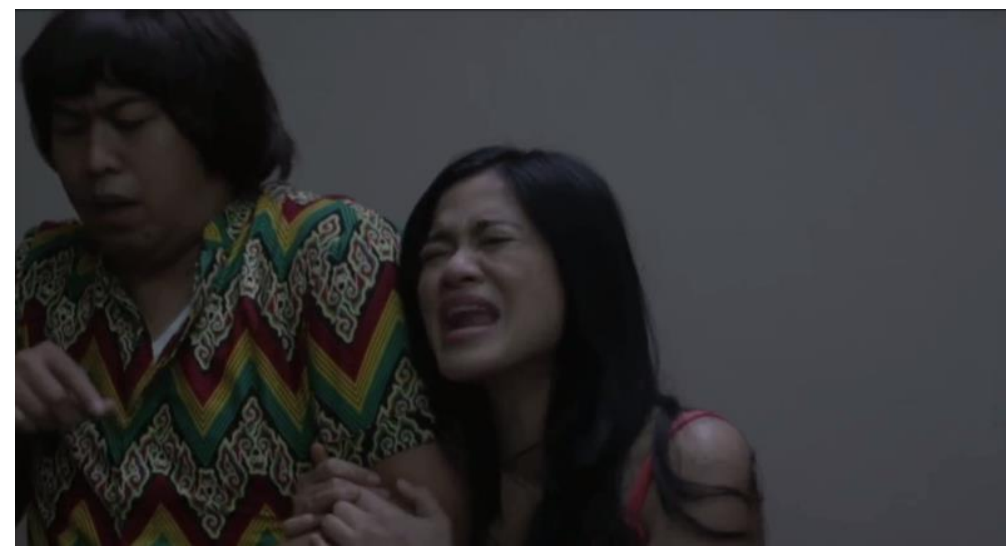

Gambar 3. Silvy Sedang Bernazar di dalam Lift Yang Mati (Sumber : Giovani, Capture Film Insya Allah Sah, 2018)

Pada gambar 3 adalah adegan yang mengisahkan Silvy tengah mengatakan Nazar yang di utarakan nya agar pintu lift dapat terbuka, terlihat kesungguhan Silvy dalam mengucapkan sehingga mengeluarkan expresi yang sangat beda . pada adegan ini adalah ketika lift terjatuh ke dasar lantai dan mengakibatkan Silvy dan Raka semakin kalud berada didalam lift dan Silvy bernazar untuk berubah menjadi wanita yang soleha, mengerjakan shalat 5 waktu, tidak minum alkohol, dan memberikan sedekah kepada yang membutuhkan. Dan konsep representasi telah di terapkan pada adegan berikut . yang mana film Insya Allah Sah menginformasikan bahwa Nazar adalah sesuatu yang di jahirkan (ucapakan), hal tersebut berkaitan dengan berjanji pada sang penguasa (Allah).

Dalam kisah dan adegan yang digambarkan pada film Insya Allah Sah, selalu memvisualkan apa yang terjadi pada kehidupan Silvy dan menjelaskan kepentingan Nazar yang telah diutarakan Silvy pada sasat Silvy dan Raka terjebak dalam lift yang mati. Beriringan dengan Silvi yang ingin menikah dengan Dion dan mempersiapkan semua kebutuhan Silvy dan Dion untuk menikah, film Insya Allah Sah memvisualkan betapa pentingnya menepati sebuah Nazar, adapun konflik yang terjadi pada persoalan hidup Silvy dan keberlangsungan pernikhan Silvy dan Dion menjadikan persiapan pernikahan Silvy dengan Dion terhambat dengan beragam permasalahan di antaranya dapat terlihat pada gambar berikut: 


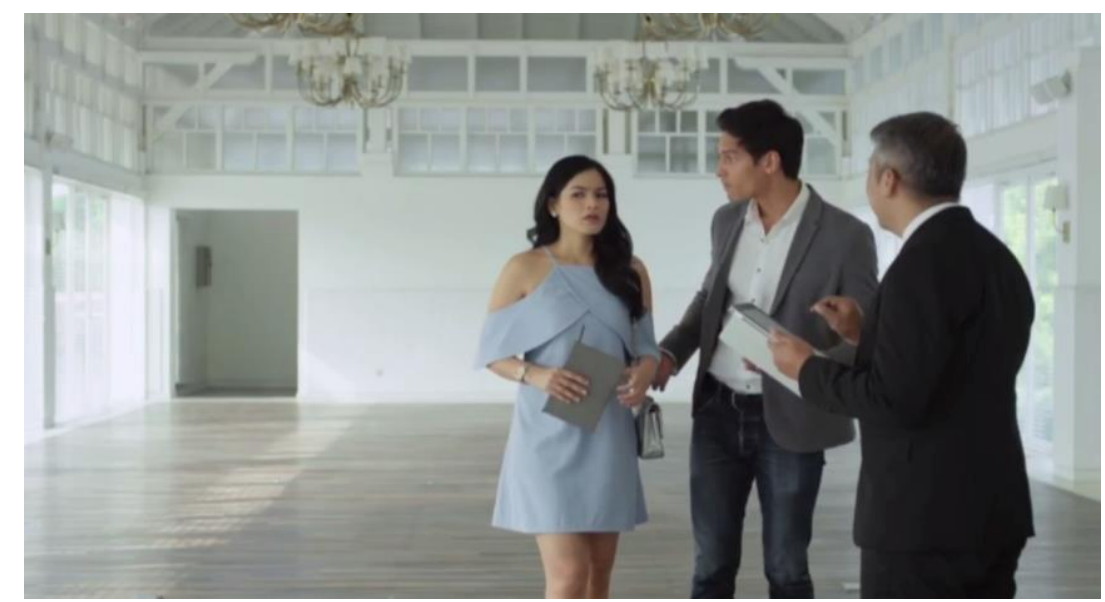

Gambar 4. Adegan Silvy dan Dion sedang menemui pemilik gedung Wedding (Sumber : Giovani, Capture Film Insya Allah Sah, 2018)

Pada gambar 4 menjelaskan dam memvisualisaikan adegan Silvy dan Dion sedang mendatangi pemilik gedung Wedding untuk pernikhan mereka. Tetapi pada saat itu gedung Wedding tidak ada yang kosong karena sudah penuh untuk tanggal pernikahan yang sudah ditentukan sebelumnya. Dalam hal ini sutradara mulai mengarahkan pada konflik yang terjadi pada film , pada adegan ini juga mulai memperlihatkan kesulitan dan hambatan yang terjadi pada Silvy untuk memenuhi keperluan untuk pernikahan Silvy karena Nazar yang di utarakan Silvy, pada gambar 4 terlihat bahwa belum terlihat perubahan yang silvy Nazarkan sebelumnya, yang mana Nazar yang Silvy utarakan sebelumnya berkaitan dengan Silvy akan berubah untuk menjadi wanita yang soleha, dalam hal ini Silvy bernazar untyuk memakai hijab dalam keseharianya, tetapi terlihat jelas belum ada perubahan fisik yang Silvy lakukan.

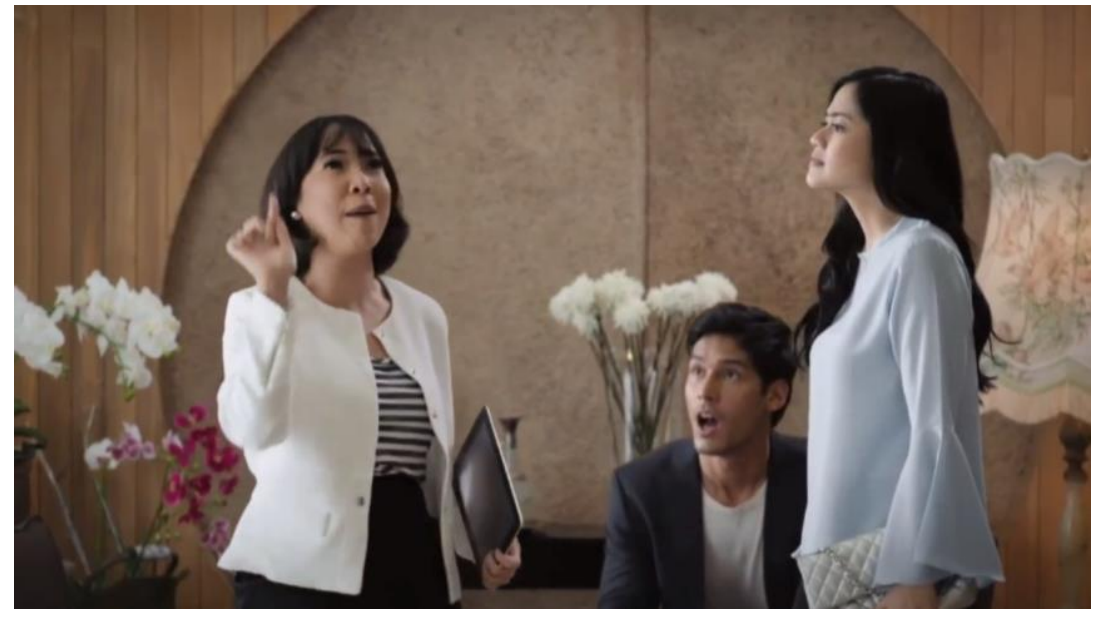

Gambar 5. Adegan Silvy dan Dion sedang menemui pemilik gedung Wedding ke2 dan menemukan masalah

(Sumber : Giovani, Capture Film Insya Allah Sah, 2018)

Film Insya Allah Sah mencoba mngedepankan akibat dan dampak yang ditimbulkan pada Silvy karena belum menepati Nazar yang dikatakana sebelumnya, Pada gambar 5 memperlihatkan adegan Silvy sedang marah dan bersitegang kepada pemilik gedung wedding, karena tidak ada juga yang bisa menerimma tanggal pernikahan yang mereka 
ajukan, film Insya Allah Sah mulai memvisualisasikan kejadian-kejadian yang menjadi konflik pada film Insya Allah.

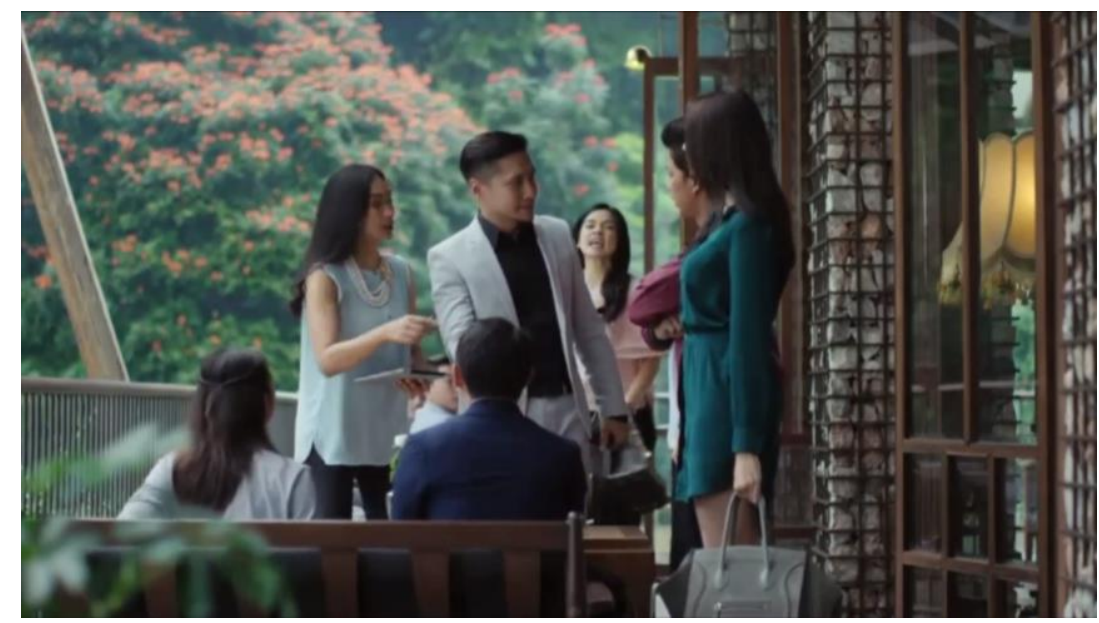

Gambar 6. Adegan Silvy tertipu dengan Wedding Organizer

(Sumber : Giovani, Capture Film Insya Allah Sah, 2018)

Pada gambar 6 menggambarakan adegan Silvy yang sedang marah disebuah restaurant karena tertipu oleh pihak Wedding Organizer gadungan. Yang mana pada hari tersebut mengisahkan sudah sangat mendekati hari pernikhan yang akan di lakukan Silvy dan Dion, tetapi belum ada satupun kebutuhan untuk pernikahan yang terselesaikan pada adegan ini produser menekankan sebuah tekanan sikologis yang sangat mendalam untuk Silvy dan menggiring silvy pada Nazar yang telah diucapkan pada adegan yang tergambarkan pada gambar 2.

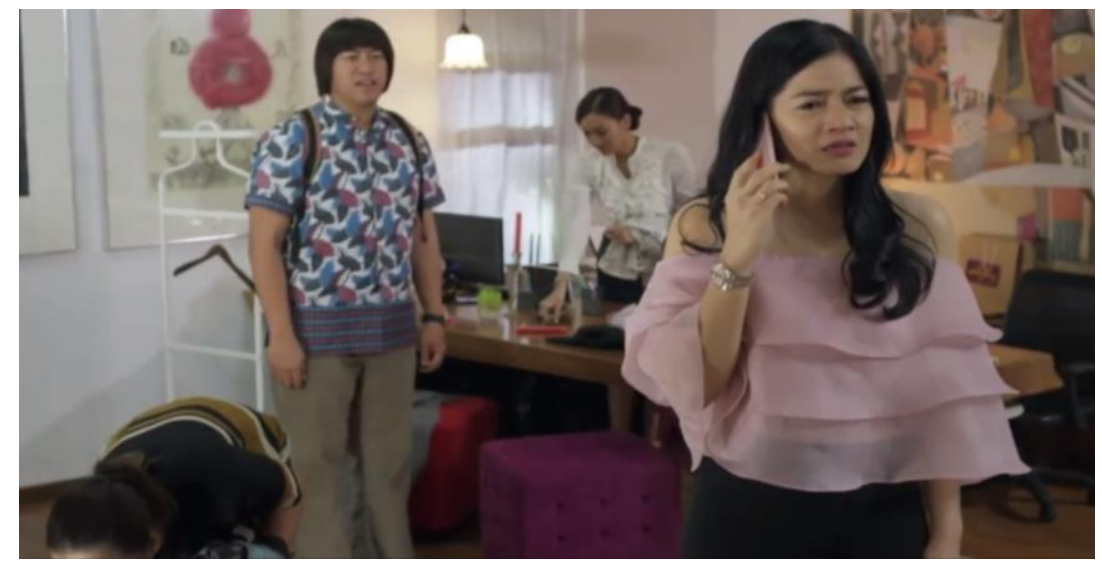

Gambar 7. Adegan Silvy Sedang menangis pada saat butik nya dirampok (Sumber : Giovani, Capture Film Insya Allah Sah, 2018)

Adapun gambar 7, memvisualisasikan titik jenuh pada karakter seorang Silvy, yang mana Silvy menangis dengan merasakan smua hal yang terjadi menimpa dirinya, bukan saja hanya hal yang berkaitan dengan pernikahan Silvy dan Dion tetapi juga menimpa urusan pribadi Silvy juga. Pada Adegan ini Raka mencoba mengingatkan kembali atas Nazar yang silvy ucapkan beberapa waktu yang lalu, untuk mengerjakan semua yang diucapkan Silvy pada saat terjebak didalam lift. Raka adalah orang yang terjebak dalam lift bersama dengan Silvy, dan Raka juga orang yang mnggiring Silvy untuk bernazar, 
dalam hal ini film Insya Allah mencoba menggambarkan bahwa Nazar adalah sebuah yang harus di tepati dan di kerjakan.

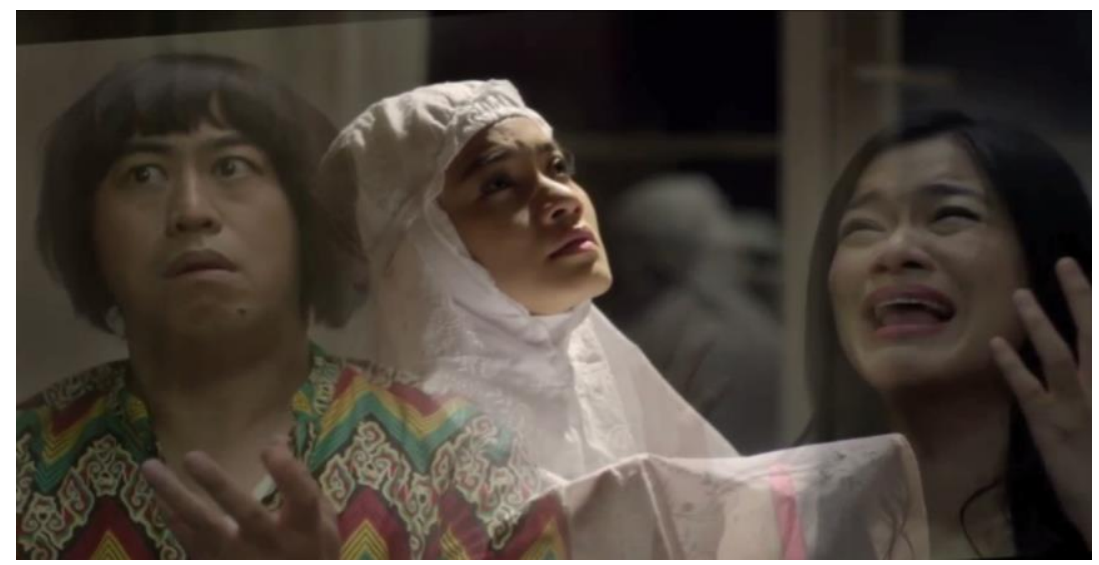

Gambar 8. Adegan Silvy Sedang sholat

(Sumber : Giovani, Capture Film Insya Allah Sah, 2018)

Pada gambar 8, memvisualisasikan Silvy sedang Shalat dan Berdoa, dimana pada frame mengambarkan dan memvisualisasikan flash back adegan yang pernah terjadi pada lift, pada titik ini film Insya Allah Sah mengisahkan bahwa ada rasa terpuruk yang sangat dalam sehingga mengakibatkan Silvy berusaha kembali pada hal yang baik dan menepati Nazarnya dan kembali mengerjakan Shalat.

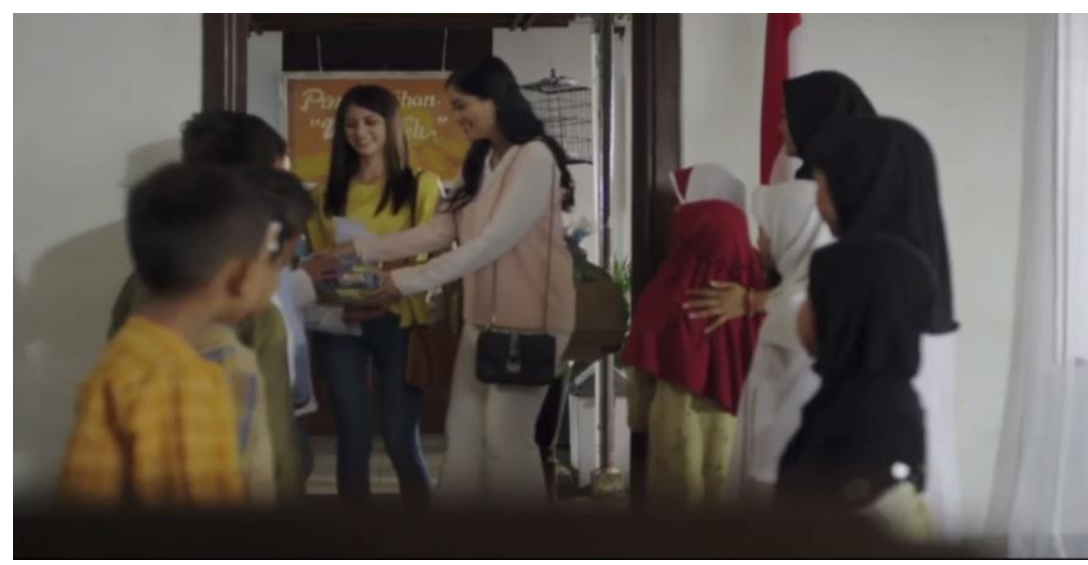

Gambar 9. Adegan Silvy Sedang Berbagi Sedekah dengan anak Yatim di Panti Asuhan (Sumber : Giovani, Capture Film Insya Allah Sah, 2018)

Film Insya Allah Sah memberikan informasi yang dimasukan pada cerita yang terdapat pada film, yang mana film Insya Allah Sah memberikan sebuah gambaran bagaimana seharusnya tindakan dan aktivitas yang seharusnya dilakukan seseorang yang telah bernazar, oleh sebab itu terdapat sebuah representasi Nazar yang begitu dalam pada film Insya Allah Sah, tidak terlepas dari jalan cerita maupun alur, tetapi visualisasi yang terdapat dalam film Insya Allah Sah sangat mengggambarkan konflik dan konstruksi dari sebuah aspek Nazar yang diterapkan dalam film. 


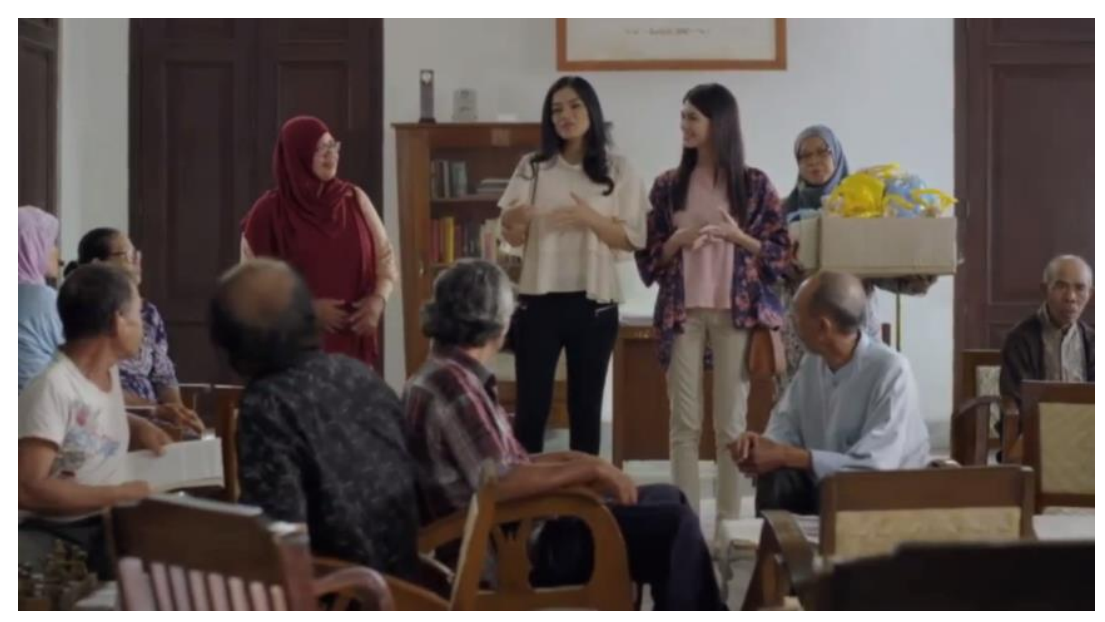

Gambar 10. Adegan Silvy Sedang Berbagi Kebahagiaan dengan para orang tua dipanti jompo (Sumber : Giovani, Capture Film Insya Allah Sah, 2018)

Pada gambar 10, menggambarkan sebuah adegan yang menggambarkan expresi dari raut wajah Silvy yang terlihat bahagia, hal tersebut terlihat pada saat setelah Silvy telah melaksanakan dan menunaikan Nazar yang telah diucapkan Silvy pada saat terjebak dalam lift. Oleh karena itu terdapat unsur representasi yang menciptakan sebuah adegan yang menggiring penonton dalam suasana yang menunjukan sebuah aktivitas yang seharusnya dilakukan oleh seseorang yang telah bernazar.

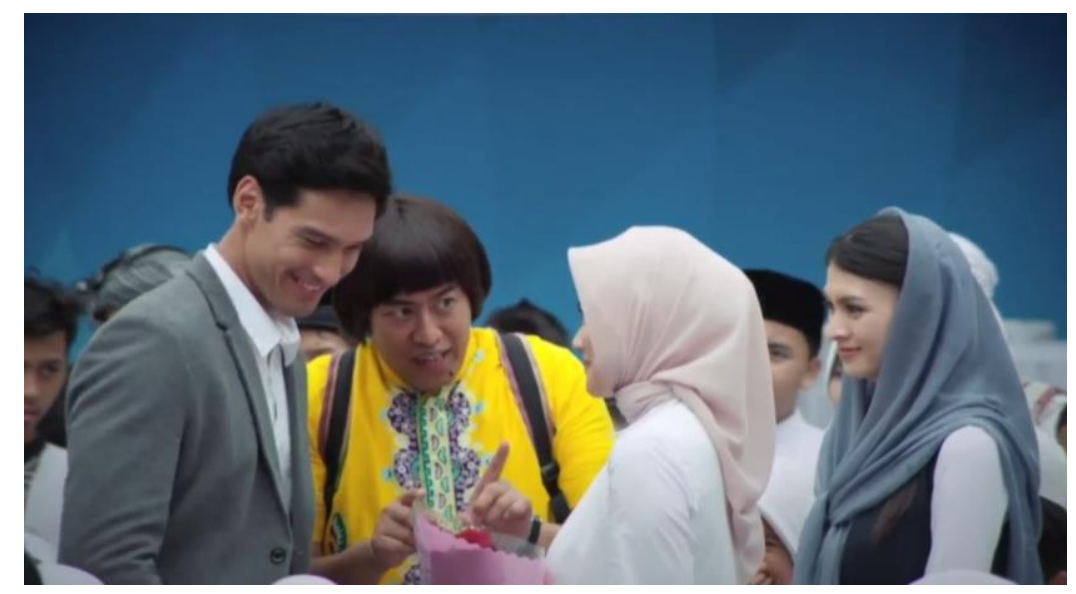

Gambar 11. Adegan Dion melamar Silvy dan senang dengan Perubahn yang Silvy lakukan (Sumber : Giovani, Capture Film Insya Allah Sah, 2018)

Film Insya Allah Sah adalah film yang menggambarkan representasi Nazar yang dituangkan kedalamnya, adapun konflik yang terjadi didalam film Insya Allah Sah adalah sebuah adegan yang disengaja untuk menggiring cerita kedalam sebuah klimaks yang menggambarkan konsep Nazar yang sebenarnya, yang mana disampaikan pesan yang divisualisasikan pada gambar 11, menggambarkan bahwa Dion mnyetujui dengan perubahan yang dilakukan oleh Silvy, karena Silvy memakan Jilbab, hal tersebut dilakukan karena Silvy melaksanakan Nazar yang telah diucapkan Silvy pada saat terjebak dalam sbuah lift dengan Raka, karena pada awalnya Dion tidak menyetujui dengan SIlvy yang berhijrah untuk berhijab. Dari smua yang silvy lakukan demi melaksanakan Nazar yang 
silvy ucapkan , film Insya Allah Sah menggambarkan kebahagiaan yang terjadi pada Silvy setelah Silvy melaksanakan Nazarnya dan pada akhir nya Silvy dan Dion baik baik saja dan smua yang di butuhkan Silvy dan Dion untuk pernikakahan mereka berjalan dengan lancer.

\section{KESIMPULAN}

Representasi Nazar Dalam Film Insya Allah Sah adalah sebuah penggambaran atau perwakilan ulang keadaan atau sebuah konflik dari realitas yang ada pada kenyataan yang sengaja dimasukan dan diimplementasikan dalam sebuah film. Hal tersebut dilakukan untuk memberikan sebuah sntuhhan pesan yang bermakna dalam film Insya Allah Sah. Tidak terlepas hanya sekedar dari alur dan cerita yang di representasikan dalam film, akan tetapi unsur sinematografi yang sangat komleks juga di implementasikan dalam sebuah film, dapat di lihat dari segi pengambilan angel yang lebih menitik beratkan pada karakter sosok Silvy sebagai pelaku Nazar, yang mana sutradara lebih menonjolkan karakter Silvy demi memberi penjelasan terhadap konsep dari pelaksanaan atau konsep menepati Nazar yang telah ddiucapkan. Representasi sendiri adalah konstruksi social yang mengharuskan kita mengeksplorasi pembentukan makna tekstual dan menghendaki penyelidikan tentang cara dihasilkannya makna pada beragam konteks. Representasi dan makna budaya memiliki materialitas tertentu yang mana dari hasil representasi akan memiliki arti dan makna yang berbeda dari setiap individu yang merasakannya sesuai dengan media dan tergantung dengan media penyampaian yang digunakan. Oleh karena itu dapat dikatakan bahwa sebuah representasi adalah sbuah penggambaran ulang realitas sosial yangbertujaun untuk mampu memberikan pesan dan mampu menggambarkan ulang realitas yang sesuai dengan adanya, demi keberlangsungan pesan yang telah di maksudkan setiap apapun yang di angkat dari sebuah film sebagai realitas kenyataan sosial di masyarakat.

Demikian hal tersebut dilakukan dalam film Insya allah sah agar tetap terjaga keoriginalitasnya dan terjaga sbuah pesan yang ingin disampaikan sesuai dengan kenyataan yang ingin di expose dalam film yakni pentingnya menpati sebuah Nazar, dan memberi sebuah informasi apa saja yang harus di lakukan seseorang ketika bernazar. Dan memperkenalkan konsep dari sebuah Nazar kepada khalayak.

Berdasarkan hasil analisis, maka dapat disimpulkan, bahwa film Insya allah Sah adalah film yang sengaja di produksi dengan penggambungan gendre yang berbeda, yakni religi dan komedi demi mampu merepresentasikan sebuah konsep realita sosial kepada khalayak agar mampu menampilkan sebuah suguhan film yang berbeda dengan film yang lain dan mampu menyampaikan pesan secara tidak menggurui penonton, dengan menggabungkan gendre komedi di dlamnya.

\section{DAFTAR PUSTAKA}

[1] Anofrina Harry (2014), Skripsi "Analisis Semiotika Representasi Persahabatan Dalam Film "Hugo".

[2] Abdullah bin nuh dan Oemar Bakry "Kamus (Aarab, Indonesia, Inggris" (1974) Jakarta. 
[3] Representasi Rasisme Perempuan Pada Film "Nothing Special" Karya Ferthamansyah. 2017. JURNAL PROPORSI Vol. 3, No.1, 47 -66 “

[4] Representasi Perempuan Dalam IKlan "Fair Of Lovely" Versi Nikah Atau S2. 2016. JURNAL Vol. IV, No.1, 47 -66“

[5] W.J.S Poerwadarminta. 1999. KAMUS UMUM BAHASA INDONESIA. Balai Kota, Jakarta

[6] Wibowo, Indiwan Seto Wahyu. (2013). Semiotika KomunikasiAplikasi Praktis Bagi Penelitian dan Skripsi Komunikasi. Jakarta: Mitra Wacana Media. 